\title{
Kinematic Synthesis of 3R-1P Geared Slider Crank Mechanism with Variable Topology Features for Motion Generation
}

\section{H. M. Naveen ${ }^{1}$, Shrinivas S. Balli² and Umesh M. Daivagna ${ }^{3}$}

${ }^{1}$ Assistant Professor, Department of Mechanical Engineering, RYM Engineering College, Ballari, Karnataka, India

${ }^{2}$ Professor, Department of Mechanical Engineering, Basaveshwar Engineering College, Bagalkot, Karnataka, India

${ }^{3}$ Professor, Department of Mechanical Engineering, Ballari Institute of Technology, Ballari, Karnataka, India

\begin{abstract}
Article Info

Volume 8, Issue 3

Page Number: 317-322

Publication Issue :

May-June-2021

Article History

Accepted : 01 June 2021

Published: 06 June 2021

The paper focuses on synthesis of slider crank mechanism consisting of a single gear as a part of input and output of the mechanism. Complex number method is used as one of the synthesis criteria. This is a planar four link gear slider mechanism having one degree of freedom which is considered for synthesis using variable topology method for the task of motion generation. The mechanism consists of three revolute and one slider joints. Synthesized mechanism exhibits the features of variable topology mechanism in different modes of operation.

Keywords : Geared Slider Crank, Complex Number Method, Variable Topology Mechanism
\end{abstract}

\section{INTRODUCTION}

The slider crank mechanism is one of the four link mechanism which arises on replacing, one of the link either input or output with a slider. The foremost aspect in kinematics of mechanisms is the synthesis of mechanism. This mechanism is synthesized on the basis of complex number method. Synthesis consists of dimensional, type and number synthesis to perform various tasks. Synthesis and Analysis are the two major categories of design process of mechanism. Synthesis process involves devising a mechanism to perform the desired task and analysis process involves functioning of the mechanism. As complexity arises in building the real mechanism and testing, this calls for software based study of the mechanisms.

\section{LITERATURE REVIEW}

This text deals with the literature review on variable topology method adapted by different people working in this area. Balli and Chand [1] intimated that, an analytical method can be used to synthesize five bar mechanism with variable topology. The work was carried out for movement between extreme positions of the mechanism for function generation. Balli and Chand [2] proposed the complex number method and utilized it to synthesize the mechanism having five links for motion and path generation tasks with 
variable topology for movement between extreme positions. Balli and Chand [3] suggested an analytical method to synthesize planar seven link mechanism with variable topology for motion between two dead centers. Gadad, Umesh M. Daivagna and Shrinivas S. Balli [4] focused on synthesis of planar seven link mechanism using triad and dyad with variable topology for the task function generation. Daivagna and Balli [5] dealt with synthesis process of an off-set five link slider mechanism with variable topology. Ren-Chung Soong, Kuei-Shu Hsu and Feng-Tsai Weng [6] applied a geared seven-bar mechanism for mechanical forming presses. Daivagna and Balli [7] synthesized a variable topology seven-bar slider mechanism to have motion between two dead-center positions. Volken, Eres Soylemez and Engin Tanik [8] presented an analysis and synthesis method for a geared four-bar mechanism. Daivagna and Balli [9] worked on the synthesis of variable topology mechanism with five-bar slider for finitely separated positions. Prashant and Balli [10] reviewed the works on variable topology method. H. M. Naveen, Shrinivas S. Balli and Umesh M. Daivagna [11] dealt with synthesis of eight link gear mechanism for motion generation. H. M. Naveen, Shrinivas S. Balli and Umesh M. Daivagna [12] dealt with synthesis of In-Line Ten Link Gear Slider Mechanism of Variable Topology. Prashant and Balli [13] synthesized a seven bar slider for limiting positions using variable topology. H. M. Naveen, Shrinivas S. Balli and Umesh M. Daivagna [14] presented the behavior of mechanism using linkage software. H. M. Naveen, Shrinivas S. Balli and Umesh M. Daivagna [15] dealt with the functional aspects of ten link gear slider mechanism. H. M. Naveen, Shrinivas S. Balli and Umesh M. Daivagna [16] worked on Phase III operating conditions in variable topology mechanism. H. M. Naveen, Shrinivas S. Balli and Umesh M. Daivagna [17] worked on alternative approaches in variable topology mechanisms. H. M. Naveen, Shrinivas S. Balli and Umesh M. Daivagna [18] dealt with transmission angles in eight link gear variable topology mechanism. H. M. Naveen, Shrinivas S. Balli and Umesh M. Daivagna [19] presented the solid edge 3D model of synthesized eight link gear variable topology mechanism. H. M. Naveen, Shrinivas S. Balli and Umesh M. Daivagna [20] presented the 3D model of ten link gear slider mechanism. Prashant and Balli [22] synthesized seven bar slider for dead center positions using variable topology method.

\section{GEARED SLIDER CRANK MECHANISM WITH VARIABLE TOPOLOGY FEATURES}

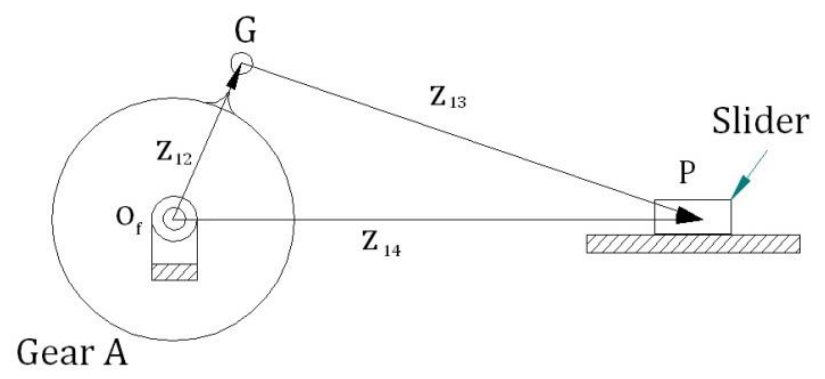

Figure 1: Schematic Representation of Geared Slider Crank Mechanism with Variable Topology Features

The Fig. 1 illustrates geared slider crank mechanism in which $\mathrm{OfG}_{\mathrm{f}}$ is the crank attached on to gear A, GP is the connecting link and $\mathrm{P}$ is the slider. Fundamental function of slider crank mechanism is that, as the crank rotates, the rotary motion of the crank is transferred to the connecting link which in turn displaces the slider in the line of action. In this way the rotary motion is converted into translator motion. Here crank acts as input link and slider $\mathrm{P}$ acts as output link.

An extension to this mechanism can be implemented by including a gear in the mechanism combination. This gear is attached to the crank and as the crank rotates, gear A also rotates with same motion. This is possible only when both crank and gear are considered to be one link. This mechanism is termed to be geared slider crank mechanism with variable topology features. The variable topological features that are possible with this type of combination are 
listed in table 1 . The mechanism can be made to operate in different modes in order to obtain multi outputs with single input.

TABLE 1. VARIABLE TOPOLOGICAL FEATURES OF GEARED SLIDER CRANK MECHANISM

\begin{tabular}{|l|l|l|}
\hline $\begin{array}{l}\text { Modes of } \\
\text { Operation }\end{array}$ & Input Link & Output Link \\
\hline Mode 1 & Crank & Slider and Gear \\
\hline Mode 2 & Gear & Crank and Slider \\
\hline Mode 3 & Slider & Crank and Gear \\
\hline
\end{tabular}

TWO POSITIONS OF GEARED SLIDER CRANK MECHANISM WITH VARIABLE TOPOLOGY FEATURES

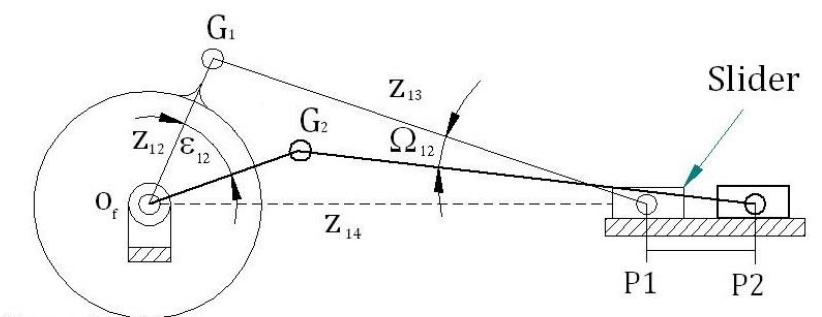

Gear A

Figure2: Schematic Representation of Geared Slider Crank Mechanism with Variable Topology Features in Two Positions

Two Position as mentioned in the earlier clause indicates the motion of the mechanism from Position 1 to Position 2 as desired by the design engineer. In the case as represented in Fig.2, the mechanism moves from Position 1 to Position 2. When an input motion of $\varepsilon_{12}$ is given to crank in clockwise direction, the link $\mathrm{O}_{\mathrm{f}} \mathrm{G}$ moves from position $\mathrm{O}_{\mathrm{f}} \mathrm{G}_{1}$ to $\mathrm{O}_{\mathrm{f}} \mathrm{G}_{2}$. $\Omega_{12}$ is the angle of rotation of connecting link in counter clockwise direction which also moves from position $\mathrm{G}_{1} \mathrm{P}_{1}$ to $\mathrm{G}_{2} \mathrm{P}_{2}$. Due to this action, slider $\mathrm{P}$ moves from $\mathrm{P}_{1}$ to $\mathrm{P}_{2}$. The mechanism is synthesized for these two finitely separated positions in further paragraphs.

\section{KINEMATIC SYNTHESIS OF GEARED SLIDER CRANK MECHANISM WITH VARIABLE TOPOLOGY FEATURES}

Writing the dyad equation for slider crank mechanism [21]

$$
\mathrm{Z}_{12}\left(\mathrm{e}^{\mathrm{i} \varepsilon 12-1}\right)+\mathrm{Z}_{13}\left(\mathrm{e}^{\mathrm{i} \Omega 12}-1\right)-(\rho-1) \mathrm{Z}_{14}=0
$$

In Eq. (1) the prescribed parameters are $Z_{12}, Z_{14}$ and the stretch ratio $\rho$. The assumed angular movements are $\varepsilon_{12}$ and $\Omega_{12}$. Only unknown $Z_{13}$ will be determined by the Eq. (2).

$$
\mathrm{Z}_{13}=\frac{(\rho-1) \mathrm{Z}_{14}-\mathrm{Z}_{12}\left(\mathrm{e}^{\mathrm{i} \varepsilon 12}-1\right)}{\left(\mathrm{e}^{\mathrm{i} \Omega 12}-1\right)}
$$

The stretch ratio is given by Eq. (3)

$$
\rho=\frac{Z_{14}+P_{12}}{Z_{14}}
$$

In Eq. (3) the $Z_{14}$ is the distance from center of gear to initial position of the slider. Further, $\mathrm{P}_{12}$ is the displacement of slider from Position 1 to Position 2.

Hence, the link length $Z_{13}$ is determined. The conventions and parameters considered in synthesis process are listed in Table 2 and Table 3.

\begin{tabular}{|c|c|}
\hline $\begin{array}{l}\text { Link (vector } \\
\text { representation and } \\
\text { angle between two } \\
\text { different positions of } \\
\text { link) }\end{array}$ & $\begin{array}{l}\text { Position } 1: \mathrm{O}_{\mathrm{f}} \mathrm{F}_{1} \mathrm{P}_{1} \\
\text { to } \\
\text { Position 2: } \mathrm{O}_{\mathrm{fG}} \mathrm{P}_{2}\end{array}$ \\
\hline $\mathrm{O}_{\mathrm{fG}}, \mathrm{Z}_{12,}, \varepsilon$ & $\varepsilon 12$ \\
\hline $\mathrm{GP}, \mathrm{Z}_{13}, \Omega$ & $\Omega_{12}$ \\
\hline Slider Displacement & $\mathrm{P}_{12}$ \\
\hline Displacement Vector: $\delta$ & $\mathrm{B}_{1} \mathrm{~B}_{2}=\delta_{12}$ \\
\hline Sign Convention & $\begin{array}{lr}\text { Counter } & \text { Clockwise } \\
(\mathrm{CCW}) & \text { motion } \\
\text { (positive) } & \\
\text { Clockwise motion }(\mathrm{CW}) \\
\text { (negative) }\end{array}$ \\
\hline
\end{tabular}

TABLE 2. CONVENTIONS TO INDICATE LINKS AND ANGLES 
TABLE 3. SUMMARY OF PARAMETERS

\begin{tabular}{|l|l|l|}
\hline $\begin{array}{l}\text { Sl. } \\
\text { No. }\end{array}$ & Description & Two Positions \\
\hline 1 & Prescribed Parameter & $\Omega_{12} \mathrm{Z}_{12}, \mathrm{Z}_{14}$ \\
\hline 2 & Free Choice & $\mathrm{P}_{12} \varepsilon 12$ \\
\hline 3 & Unknown & $\mathrm{Z}_{13}$ \\
\hline 4 & No. of Solutions & $\infty^{1}$ \\
\hline 5 & Total No. of Solutions & $\infty 1$ \\
\hline
\end{tabular}

\section{AN ILLUSTRATION}

Synthesize a geared slider crank mechanism as shown in Fig.1 with variable topology features for the following specifications. All dimensions considered are in $\mathrm{mm}$.

$\mathrm{Z}_{12}=5+22 \mathrm{i}$

$\mathrm{Z}_{14}=62+0 \mathrm{i}$

$\Omega_{12}=10^{\circ} \mathrm{CCW}$

From Eq. (2), $Z_{12}, Z_{14}, \Omega_{12}$ and stretch ratio $\rho$ are prescribed. Angular movements of links $\varepsilon_{12}$ and linear displacement $\mathrm{P}_{12}$ are free choice. Solving the equation determines the value $Z_{13}=59.0-25.8 i$

Magnitude: $\left|\mathrm{Z}_{13}\right|=\mathrm{GP}=64.3$

Hence, the link lengths $Z_{13}$ is determined.

Thus, the determined parameters of geared slider crank mechanism with variable topology features are

$\left|\mathrm{Z}_{12}\right|=\mathrm{OfG}=22.5 \mathrm{~mm}$

$|\mathrm{Z} 13|=\mathrm{GP}=64.3 \mathrm{~mm}$

$\left|\mathrm{Z}_{14}\right|=\mathrm{O}_{\mathrm{f}} \mathrm{P}=62 \mathrm{~mm}$

$\left|\mathrm{P}_{12}\right|=\mathrm{P}_{1} \mathrm{P}_{2}=18 \mathrm{~mm}$

\section{CONCLUSION}

The concept presented in this paper demonstrates that a geared slider crank mechanism can be put forward for multiple outputs with implementation of gears having higher pair of contact provided with single input to the mechanism. The output provided by the gear can be utilized for pairing another gear to the existing gear which in turn provides the necessary action. Rack and pinion arrangement can also be provided in order to have linear displacement output. Modes of operating the mechanism are one of the added advantages which the mechanism exhibits under variable topology features of the synthesized mechanism.

\section{REFERENCES}

[1]. Shrinivas S. Balli and Satish Chand, "Synthesis of a five-bar mechanism with variable topology for motion between extreme positions (SYNFBVTM)," Mechanism and Machine Theory, vol. 36, no.10, pp. 1147-1156, 2001.

[2]. Shrinivas S. Balli and Satish Chand, "Five-bar motion and path generators with variable topology for motion between extreme positions," Mechanism and Machine Theory, vol. 37, no. 11, pp. 1435-1445, 2002.

[3]. Shrinivas S. Balli and Satish Chand, "Synthesis of a planar seven-link mechanism with variable topology for motion between two dead-center positions," Mechanism and Machine Theory, vol.38, no. 11, pp. 1271-1287, 2003.

[4]. G. M. Gadad, Umesh M. Daivagna and Shrinivas S. Balli, "Triad and dyad synthesis of planar seven-link mechanisms with variable topology", National Conference on Machines and Mechanisms (NaCoMM '05), pp. 67-73, 2005.

[5]. Umesh M. Daivagna and Shrinivas S. Balli, "FSP Synthesis of an off-set five bar-slider mechanism with variable topology", National Conference on Machines and Mechanisms (NaCoMM '07), pp. 345-350, 2007.

[6]. Ren-Chung Soong, Kuei-Shu Hsu and FengTsai Weng, "A Programmable Geared Sevenbar Mechanism for Mechanical Forming Presses", Journal of the Chinese Society of Mechanical Engineers, Vol.29, No.1, pp.61-67, 2008. 
[7]. Umesh M. Daivagna and Shrinivas S. Balli, "Synthesis of a Seven-Bar Slider Mechanism with Variable Topology for Motion between Two Dead-Center Positions", World Congress on Engineering, Vol. II, pp. 1454-1459, 2010.

[8]. Volken Parlaktas, Eres Soylemez and Engin Tanik, "On the synthesis of a geared four-bar mechanism", Mechanism and Machine Theory, Vol.45, Issue 8, August 2010.

[9]. Umesh M. Daivagna and Shrinivas S. Balli, "Synthesis of Five-Bar Slider Mechanism with Variable Topology for Finitely Separated Positions", Advances in Mechanical Engineering, vol.2011, 2011.

[10]. Prashant B. Tadalagi and Shrinivas S. Balli, “A Review on Mechanisms with Variable Topology (Revisiting the Variable Topology Mechanism)", IOP Conf. Series: Materials Science and Engineering, Vol. 691, pp. 012047(1-9), 2019.

[11]. H. M. Naveen, Shrinivas S. Balli and Umesh M. Daivagna, "Two FSP Synthesis of Eight Link Gear Mechanism for Motion Generation with 9R-1G Joints", International Journal of Engineering Applied Science and Technology, Vol. 5, No. 3, pp. 288-294, 2020.

[12]. H. M. Naveen, Shrinivas S. Balli and Umesh M. Daivagna, "Kinematic Synthesis of In-Line Ten Link Gear Slider Mechanism of Variable Topology with 12R-1G-1P Joints", International Research Journal of Engineering and Technology, Vol. 7, No. 8, pp. 605-610, 2020.

[13]. Prashant B. Tadalagi and Shrinivas S. Balli, "Limiting Positions Synthesis of Seven Bar Slider Automated Fiber Placement Mechanism for Motion Generation using Variable Topology", International Journal of Mechanical and Production Engineering Research and Development (IJMPERD), Vol. 10, Issue 3, pp. 13297-13308, 2020.
[14]. H. M. Naveen, Shrinivas S. Balli and Umesh M. Daivagna, "Study of Characteristic Behavior of Synthesized Variable Topology Mechanism using Linkage Software”, GIS Science Journal, Vol. 7, No.8, pp. 160-166, 2020.

[15]. H. M. Naveen, Shrinivas S. Balli and Umesh M. Daivagna, "Functional Aspects of Synthesized In-Line Ten Link Gear Slider Mechanism of Variable Topology using Linkage Software", International Research Journal of Engineering and Technology, Vol. 7, No.9, pp. 3281-3286, 2020.

[16]. H. M. Naveen, Shrinivas S. Balli and Umesh M. Daivagna, "Possible Configurations and Coupler Curves of Eight Link Gear Variable Topology Mechanism in Phase III Operating Condition", International Research Journal of Engineering and Technology, Vol. 7, No. 11, pp. 502-509, 2020.

[17]. H. M. Naveen, Shrinivas S. Balli and Umesh M. Daivagna, "Alternative Approaches in Variable Topology as Applied to Degree(s) of Freedom and Modes of Operation in Mechanisms", International Journal of Advances in Engineering and Management, Vol. 2, No. 9, pp. 442-449, 2020.

[18]. H. M. Naveen, Shrinivas S. Balli and Umesh M. Daivagna, "Transmission Angles in Synthesized Eight Link Gear Mechanism of Variable Topology with Characteristic Output", International Journal of Engineering Sciences \& Research Technology, Vol. 10, Issue 2, pp. 6068, 2021.

[19]. H. M. Naveen, Shrinivas S. Balli and Umesh M. Daivagna, "Solid Edge 3D Model of Synthesized Eight Link Gear Variable Topology Mechanism", International Journal of Computer Techniques, Vol. 8, Issue 2, pp. 163-170, 2021.

[20]. H. M. Naveen, Shrinivas S. Balli and Umesh M. Daivagna, "Solid Edge 3D Model of Synthesized In-Line Ten Link Gear Slider Variable Topology Mechanism", International Research 
Journal of Engineering and Technology, Vol. 8, No. 4, pp. 3056-3061, 2021.

[21]. George N. Sandoor and Arthur G. Erdman, Advanced Mechanism Design: Analysis and Synthesis, Vol. II, Prentice-Hall, Englewood Cliffs, New Jersey, 1984.

[22]. Prashant B. Tadalagi and Shrinivas S. Balli, "Dead Centre Positions Synthesis off offset Seven Bar Slider Mechanism for Motion Generation using Variable Topology" , GIS Science Journal, Vol. 8, No.5, pp. 1613-1620, 2021.

\section{Cite this article as :}

H. M. Naveen, Shrinivas S. Balli, Umesh M. Daivagna, " Kinematic Synthesis of 3R-1P Geared Slider Crank Mechanism with Variable Topology Features for Motion Generation, International Journal of Scientific Research in Science, Engineering and Technology(IJSRSET), Print ISSN : 2395-1990, Online ISSN : 2394-4099, Volume 8, Issue 3, pp.317-322, May-June-2021. Available at Journal URL : https://ijsrset.com/IJSRSET218363 